\title{
Behavioral Responses of Captive Corvids to the Presence of Visitors
}

\author{
Claudia A. F. Wascher ${ }^{1, *}$, Niklas Baur ${ }^{2}$, Marietta Hengl ${ }^{3}$, Carina Köck ${ }^{3}$, Teresa Pegger ${ }^{3}$, \\ Julia Schindlbauer ${ }^{3}$, and Laura Wemer ${ }^{3}$
}

${ }^{1}$ School of Life Sciences, Anglia Ruskin University, Cambridge, UK

${ }^{2}$ Messerli Research Institute, Department of Comparative Cognition, University of Veterinary Medicine Vienna

${ }^{3}$ Core facility Konrad Lorenz Forschungsstelle for Behaviour and Cognition, University of Vienna

*Corresponding author (Email: claudia.wascher@gmail.com)

Citation - Wascher, C. A. F., Baur, N., Hengl, M., Köck, C., Pegger, T., Schindlbauer, J., \& Wemer, L. (2021). Behavioral responses of captive corvids to the presence of visitors. Animal Behavior and Cognition, 8(4), 481-492. https://doi.org/10.26451/abc.08.04.03.2021

\begin{abstract}
Behavioral responses of captive animals to the presence of visitors in zoos and wildlife parks can be interpreted as signs of negative (disturbance), neutral or positive (enrichment) welfare. In the present study, we investigated behavioral responses of captive common ravens, Corvus corax and crows, Corvus corone, to the presence of visitors in general and to the proximity or distance of visitors to the aviary respectively. Duration of affiliative behaviors, feeding and stress-related behaviors did not change when visitors were present compared to control situations without visitors being present. Both corvid species showed less head up behavior when visitors were in sight compared to the control condition. In contrast, preening of crows significantly increased when visitors were within two meters of the aviary compared to the control condition. The same relationship was found in regard to increase in vocalization for common ravens, but not for crows. Our results indicate that corvids, housed in a wildlife park for several years, still show behavioral responses to the presence of human visitors in close proximity to their enclosure. Overall, we did not find clear indications for reduced welfare due to visitor presence, such as increased locomotion or stress-related behaviors. We therefore conclude that the described behavioral changes are not indicative of any negative welfare impacts of visitor presence.
\end{abstract}

Keywords - Animal welfare, Crows, Common ravens, Visitor effects

The presence of visitors is a prominent feature of zoo and wildlife park environments. Captive individuals from a wide variety of species have been shown to behaviorally respond to the presence of visitors, which generally can be seen as an adaptation to cope with their environment. Depending on the type (qualitative response) and magnitude (quantitative response) of behavioral response, changes in behavior are usually judged as visitors having a positive, negative or neutral effect on captive non-human animals' welfare (reviewed in Hill \& Broom, 2009; Sherwen \& Hemsworth, 2019). The impact visitors have on captive animals was termed 'visitor effects' by Hosey (2000). Previous research investigated the effects of noise level and interactions with the animals (reviewed in Davey, 2007). If humans are perceived as a threat, e.g., as predators or competitors, presence of visitors will likely have negative welfare impacts. In terms of behavioral responses of captive animals to visitors, behaviors like increased rates of aggression between conspecifics, avoidance (fleeing or retreating), inhibition of movement (freezing), vigilance, certain vocalizations (alarm calls) or stereotypies are commonly interpreted as signs of negative welfare (Sherwen \& Hemsworth, 2019). A number of species have been shown to increase behaviors indicative of restricted welfare in the presence of visitors (cotton topped tamarins, Saguinus 
oedipus oedipus: Glatston et al., 1984; Indian gaur, Bos gaurus gaurus: Sekar et al., 2008; lion-tailed macaques, Macaca silenus: Mallapur et al., 2005; little penguins, Eudyptula minor: Sherwen, Magrath, et al., 2015; quokka, Setonix brachyurus: Learmonth et al., 2018; white handed gibbons, Hylobates lar: Cooke \& Schillaci, 2007). An additional factor affecting behavioral responses of captive animals is visitor density. Captive western lowland gorillas, Gorilla gorilla gorilla, show more behaviors suggesting relaxation, e.g., resting, at low visitor densities, and more behaviors indicative of negative welfare, e.g., intragroup aggression and stereotypies, at high visitor densities (Carder \& Semple, 2008; Wells, 2005). Increased visitor group sizes are associated with increased activity, e.g., in Diana monkeys, Cercopithecus diana diana (Todd et al., 2007) and jaguars, Panthera onca (Sellinger \& Ha, 2005) and more hiding behavior, e.g., in harbour seals, Phoca vitulina (Stevens et al., 2013). Japanese macaques, Macaca fuscata, performing in a cognitive task were significantly less successful in the presence of large visitor crowds, compared to smaller groups (Huskisson et al., 2020). A group of captive orangutans played less and observed visitors more, when they were in close proximity (Choo et al., 2011). Koalas, Phascolarctos cinereus, showed more behavioral changes indicative of a negative impact on welfare in response to loud compared to calm visitors, indicating that not only visual stimuli, but also anthropogenic noise might affect the welfare of captive animals (Birke, 2002; Larsen et al., 2014; Maia et al., 2012). Diurnal species are usually more negatively affected by the presence of visitors compared to nocturnal ones (Queiroz \& Young, 2018).

A number of domestic species (pygmy and mixed-breed goats, Capra hircus ssp.; llama, Llama glama, and Vietnamese pot-bellied pigs, Sus scrofa: Farrand et al., 2014); California sea lions, Zalophus californianus (de Vere, 2018); greater rheas, Rhea americana (de Azevedo \& Lima, 2012); Kangaroo Island kangaroos, Macropus fuliginosus fuliginosus, and red kangaroos, Macropus rufus (Sherwen, Hemsworth, et al., 2015); meerkats, Suricata suricatta (Sherwen et al., 2014), showed minimal behavioral responses to the presence of visitors, indicating no significant effect on their welfare. The potential negative welfare impact of visitors' presence on captive animals can not only be measured in behavioral, but also physiological parameters. In several studies, the activation of the physiological stress response has been shown to be affected by visitors. A number of species show increased hypothalamic-pituitaryadrenal (HPA) axis activity in response to the presence of visitors: black-capped capuchins, Cebus apella (Sherwen, Harvey et al., 2015); spider monkeys, Ateles geoffroyii rufiventris (Davis et al., 2005); Indian blackbuck, Antelope cervicapra (Rajagopal et al., 2011). Exposure to visitors can cause chronic stress in captive animals in zoos and wildlife parks, causing stress disorders (Maple \& Perdue, 2013). In addition to the factors already mentioned, levels of anthropogenic noise, type of interaction, environmental factors such as season, weather, time of day, and exhibit design can also affect behavioral responses to visitors (Davey, 2006, 2007; Goodenough et al., 2019). Careful consideration of exhibit design, species characteristics and interventions regarding visitor education can positively impact captive animal welfare (Fernandez et al., 2009). Certain levels of habituation to the presence of visitors are expected in animals housed in captivity long-term (Cipolletta, 2003). Hence, no behavioral changes in response to visitor presence are expected after a certain period of time. Humans might also be perceived as enrichment or social partners and might thus have a positive welfare impact (Claxton, 2011).

Most research on visitor effects has been conducted on primates or at least mammalian species. In the present study, we investigated behavioral responses of captive crows, Corvus corone and common ravens, Corvus corax, in response to the presence of zoo visitors. Corvids are a prime avian model system in the study of cognition, with many studies being conducted on captive corvids. A number of cognitive paradigms require close interactions with human experimenters (Dufour et al., 2012; Hillemann et al., 2014). This also poses a challenge to working with corvids, as many species show pronounced neophobia (Greggor et al., 2015, 2016). In captivity, corvids develop relationships with caretakers and experimenters. They participate more in experimental tasks with long term familiar experimenters compared to people they were only familiar with for shorter periods of time (Cibulski et al., 2014) and remember positive or negative outcomes of interactions with experimenters after a single encounter (Müller et al., 2017). Several corvid species have been shown to differentiate between familiar from unfamiliar humans (Davidson et al., 2015; Wascher et al., 2012) and possess long-term memory of 
humans perceived as dangerous (Blum et al., 2020; Marzluff et al., 2010, 2012). Ravens are responsive to human gaze cues and captive and hand-raised ravens have been shown to follow an experimenter's gaze around a visual barrier (Bugnyar et al., 2004). Amazingly, even wild corvids are sensitive to attentional cues of humans (Clucas et al., 2013; Davidson et al., 2015). Wild crows attracted to zoos as a source of food avoided visitors and were observed most during times with low visitor numbers (Kövér et al., 2019).

Here, we investigated common ravens' and carrion crows' behavioral responses to the presence of visitors and effects of the visitors' distance to the enclosure (further than two meters apart vs. closer than two meters). We investigated the duration of aggressive and affiliative behaviors, preening, feeding, head up, a form of vigilance with relaxed body posture, i.e., neck not stretched, locomotion, vocalizations, and stress-related behaviors, which included shaking the whole body, beak wiping and wing quivering. Displacement behaviors can be indicative of stress and reflect increased autonomic arousal in non-human animals (Troisi, 2002). In a previous study, the frequencies of stress-related behaviors have been shown to increase in stressful contexts in crows (Spreafico et al., 2012) and similar behavioral indicators of stress have been used for example to investigate the stress-reducing effect of post-conflict affiliation (Castles \& Whiten, 2010; Fraser et al., 2008). However, it also needs to be noted that all of the behaviors considered here occur in different stress-related and not stress-related contexts. For example, wing quivering can occur in stressful context but also during maintenance behavior, beak wiping can occur in stressful context but also in feeding context when cleaning the beak. If the presence of visitors had a negative effect on captive corvids welfare, we would predict an increase in frequency of agonistic encounters between conspecifics (Sherwen \& Hemsworth, 2019), preening, locomotion and stress-related behaviors (Carder \& Semple, 2008). Further, a decrease in affiliative behaviors and feeding would similarly indicate a negative impact on welfare (Sherwen \& Hemsworth, 2019). Similarly, an increase in affiliative behaviors and feeding could be indicative of a neutral effect or even a positive effect of visitor presence.

\section{Method}

\section{Study Subjects and Ethics Statement}

Data were collected in July 2015 from a population of captive corvids housed in outdoor aviaries

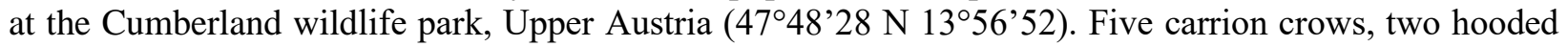
crows and one hybrid (4 males, 4 females; hatching 2007 - 2014; Corvus corone) and four common ravens ( 2 males, 2 females; hatching 2009; Corvus corax) participated in the study. All individuals were hand-raised, and pair-housed in large outdoor enclosures (crows: $20 \mathrm{~m}^{2}$; ravens: $80 \mathrm{~m}^{2}$ per pair). They were never deprived of food, and water was available ad libitum for drinking and bathing. Corvids were fed once a day in the morning. Birds received a mixed diet consisting of meat, fruits, bread, milk products. Both common ravens and carrion crows are food caching species, so they would cache some of the food, which would be available to them over the course of the day. This study complied with Austrian and local government guidelines. Individuals remain captivity housed in the Cumberland game park and the Konrad Lorenz Forschungsstelle (KLF) (under the license AT00009917), before and after completion of the present study. Data collection was entirely non-invasive, and no further animal experimental license was required.

\section{Data Collection}

Data were recorded on nine consecutive days from the $9^{\text {th }}$ to the $17^{\text {th }}$ of July 2015 between 0700 and 1900. The study was intended to investigate relative short-term behavioral effects of visitor presence during a period with relatively high visitor numbers (July). On average, approximately 48 visitors were recorded during each day of data collection (3 to 89). Focal observations were video recorded by six observers synchronously (NB, MH, CK, TP, JS, LW). The observers calmly sat on the ground at a distance of approximately five meters from the aviary. The focal subjects were familiarized to the presence of human observers for two days prior to the start of data collection. Corvids previously have 
been shown to differentiate between familiar and unfamiliar humans (Cibulski et al., 2014; Wascher et al., 2012); hence, we assume they recognize observers as familiar humans, whereas most zoo visitors will be unfamiliar humans. Each focal observation lasted for $25 \mathrm{~min}$, and data were recorded in blocks of two hours, so in each block, each focal individual was recorded twice. Whether observations started on the male or the female and at which aviary, was pseudo-randomized. The observers noted whenever visitors came within sight of the focal individual and when they approached the aviary closer than two meters. The distance to the aviary was measured for each enclosure at the beginning of the study and marked with a stone on the ground. Visitors could potentially approach the aviary up to $0.5 \mathrm{~m}$, where a wooden fence prevents them from coming closer. Additionally, the approximate number of visitors was noted.

\section{Data Analyses}

Videos were analyzed by NB, MH, CK, TB, JS or, LW using Solomon Coder beta 17.03.27 (András Péter, www.solomoncoder.com). As the presence of visitors had been acoustically noted on the videos, they could not be coded blind. An inter-observer reliability analysis using the Kappa statistic was performed on $20 \%$ of randomly chosen events, which were coded by a second observer (CW); Cohen's K affiliation $=.868$, preening $=.823$, eating $=.914$, head up $=.795$, locomotion $=.892$, vocalizations $=.914$, stress-related $=.903$ ).

We analyzed periods of $10 \mathrm{~s}$, with or without humans present. On average, visitors spent $98 \mathrm{~s}$ (minimum \pm maximum: $5 \pm 2201 \mathrm{~s}$ ) in sight of focal individuals and $66 \mathrm{~s}$ within two meters (minimum \pm maximum: $5 \pm 1159 \mathrm{~s}$ ). Because of the high variation in time in which visitors were visible to the focal subjects, we decided to standardize the observed time period. We recorded 456 events with visitors in sight of the corvids (23 - 52 events per individual; $M \pm S D$ : $38 \pm 9$ ) and 651 'control' events, with no visitors in sight of the birds (40 - 67 events per individual; $M \pm S D$ : $54 \pm 10$ ). Visitor events and control events always occurred in the same two hours block, to reduce effects of time of day, weather, or any other potential co-variates. The birds' behavior was analyzed for the first ten seconds that the visitors were within sight of the birds or closer than $2 \mathrm{~m}$ to the aviary. We recorded the duration of aggressive (e.g., displacement, threat, fight) and affiliative behaviors (allo-preening and sitting in contact), preening, eating, head up, locomotion, vocalizations, and stress-related behaviors, which included shaking, beak wiping and wing quivering. No occurrences of aggression have been observed and hence, this behavior was not analyzed.

\section{Statistical Analysis}

Statistical analyses were performed in R 3.2.2 (R Core Team). We used linear mixed-effects models in package nlme (Pinheiro et al., 2020) to differentiate behavior between conditions. Species (crows and common ravens), visitor condition (visitors present and closer than two $\mathrm{m}$, visitors present and further than two meters, no visitors present), and the interactions between species and visitor status were included as fixed factors. For each model, individual identity was included as a random term to control for repeated samples of the same individuals and unbalanced design. Various model diagnostics were employed to confirm model validity (visual inspection of distribution of residuals, qq plots, residuals plotted against fitted values) of which none suggested violation of model assumptions. To assess multicollinearity between fixed factors, we calculated variance inflation factors (VIFs) using the vif function in the package car (Fox \& Weisberg, 2011). VIFs for all factors were below 2, indicating that there was no issue with multicollinearity (Zuur et al., 2009). To describe the variance explained by our models, we provided marginal and conditional $\mathrm{R}^{2}$ values that range from 0 to 1 and described the proportion of variance explained by the fixed and by the fixed and random effects combined, respectively (Nakagawa \& Schielzeth, 2013). We calculated marginal and conditional $\mathrm{R}^{2}$ values using the r.squaredGLMM function in MuMIn (version 1.43.6; Barton, 2019). Levels of significance were adjusted to $p<.007$ according to the Bonferroni correction, to account for multiple testing of seven behavioral 
parameters. All datasets and the $\mathrm{R}$ script used to conduct the statistical analyses are available as supplementary files.

\section{Results}

Duration of affiliative behavior, feeding and stress-related behaviors were neither affected by species nor visitor condition (Table 1; affiliative behavior: $14 \%$ explained by all fixed factors together ( $\mathrm{R}^{2}$ marginal); additional $54 \%$ of the variation was explained by the random factor $\left(\mathrm{R}^{2}\right.$ conditional); feeding: $6 \% \mathrm{R}^{2}$ marginal; $4 \% \mathrm{R}^{2}$ conditional; stress related behaviors: $12 \% \mathrm{R}^{2}$ marginal; $73 \% \mathrm{R}^{2}$ conditional). Crows preened more when visitors were within two meters of their aviary compared to the control condition without visitors present (Table 1; Figure 1). Overall, $22 \%$ of the variation in preening was explained by all fixed factors together ( $\mathrm{R}^{2}$ marginal), and an additional $3 \%$ of the variation was explained by the random factor ( $\mathrm{R}^{2}$ conditional). Corvids showed less head up behavior when visitors were in sight compared to the control condition (Table 1; Figure 2; $22 \% \mathrm{R}^{2}$ marginal; $38 \% \mathrm{R}^{2}$ conditional). Common ravens vocalized more when visitors were within two meters of their aviary compared to the control condition (Table 1; Figure 3). This relationship was missing in crows. Overall, $88 \%$ of the variation in vocalizations was explained by all fixed factors together ( $\mathrm{R}^{2}$ marginal), and no additional variation was explained by the random factor $\left(\mathrm{R}^{2}\right.$ conditional).

\section{Figure 1}

Mean Duration and Standard Error of Preening in Seconds per Visitors' Condition in Crows (Grey) and Ravens (Black)

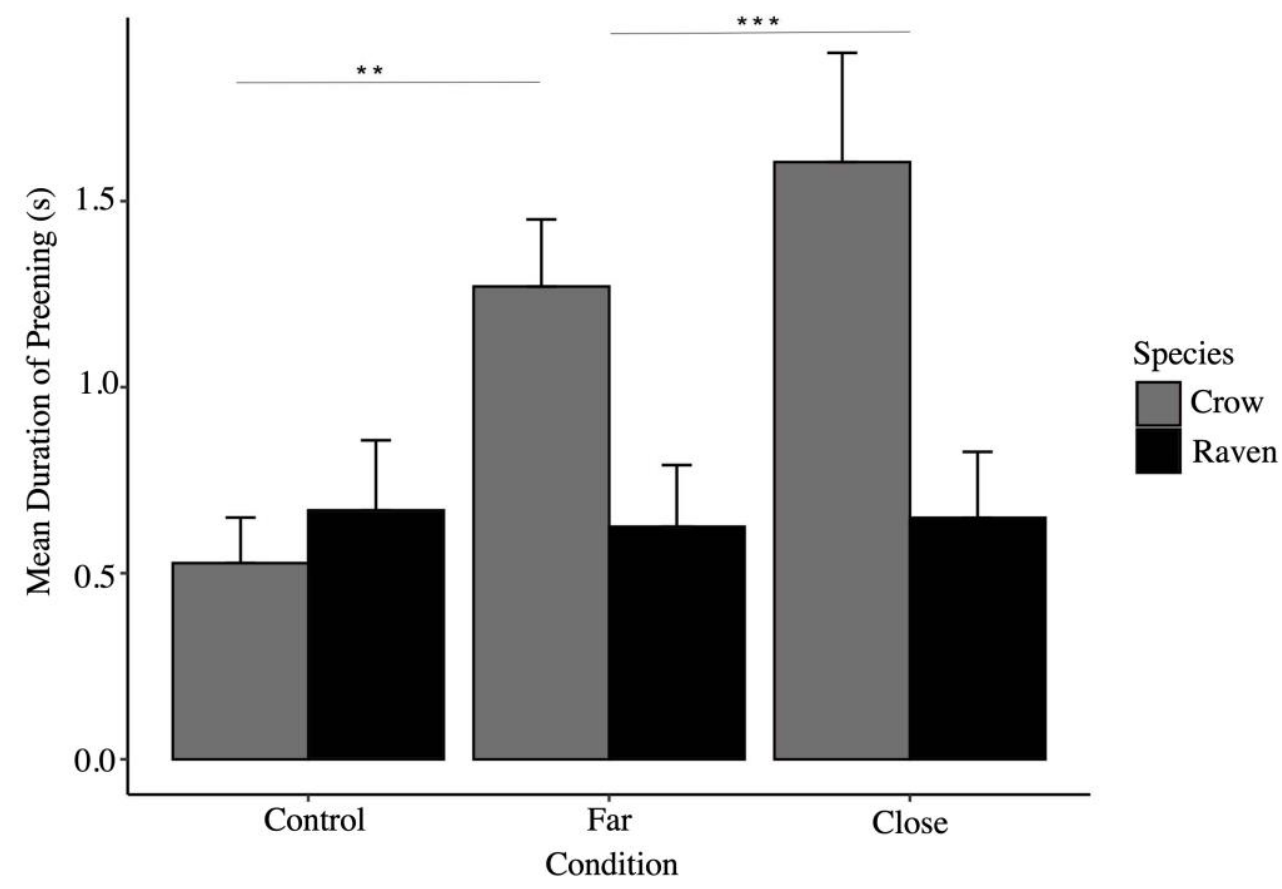

Note. ${ }^{* *} p \leq .07 ; * * p \leq .001$. 
Table 1

Results of the Generalized Mixed Linear Model Investigating Factors Affecting Patterns of Behavior

\begin{tabular}{|c|c|c|c|c|}
\hline Response Variable & Parameter & Estimate $\pm \mathrm{SE}$ & z-value & $p$-value \\
\hline affiliation & $\begin{array}{l}\text { (intercept) } \\
\text { species } \\
\text { condition (control relative to visitors close) } \\
\text { condition (control relative to visitors far) } \\
\text { species*condition (control relative to } \\
\text { visitors close) } \\
\text { species*condition (control relative to } \\
\text { visitors far) }\end{array}$ & $\begin{array}{l}0.462 \pm 0206 \\
0.221 \pm 0.163 \\
-0.184 \pm 0.211 \\
-0.182 \pm 0.163 \\
0.109 \pm 0.311 \\
0.507 \pm 0.276\end{array}$ & $\begin{array}{l}2.237 \\
0.624 \\
-0.871 \\
-1.112 \\
0.352 \\
1.832\end{array}$ & $\begin{array}{l}.025 \\
.546 \\
.383 \\
.266 \\
.724 \\
.067\end{array}$ \\
\hline preening & $\begin{array}{l}\text { (intercept) } \\
\text { species } \\
\text { condition (control relative to visitors } \\
\text { close) } \\
\text { condition (control relative to visitors far) } \\
\text { species*condition (control relative to } \\
\text { visitors close) } \\
\text { species*condition (control relative to } \\
\text { visitors far) }\end{array}$ & $\begin{array}{l}\mathbf{0 . 5 3} \pm \mathbf{0 . 1 5 8} \\
0.143 \pm 0.267 \\
\mathbf{1 . 0 7 9} \pm \mathbf{0 . 2 7 2} \\
\mathbf{0 . 7 4 3} \pm \mathbf{0 . 2 1 1} \\
\mathbf{- 1 . 1 0 2} \pm \mathbf{0 . 4} \\
-0.786 \pm 0.357\end{array}$ & $\begin{array}{l}3.355 \\
0.536 \\
\mathbf{3 . 9 6 5} \\
\mathbf{3 . 5 1 1} \\
\mathbf{- 2 . 7 5 3} \\
-2.202\end{array}$ & $\begin{array}{r}<.001 \\
.603 \\
<.001 \\
<.001 \\
.006 \\
.027\end{array}$ \\
\hline eating & $\begin{array}{l}\text { (intercept) } \\
\text { species } \\
\text { condition (control relative to visitors close) } \\
\text { condition (control relative to visitors far) } \\
\text { species*condition (control relative to } \\
\text { visitors close) } \\
\text { species*condition (control relative to } \\
\text { visitors far) }\end{array}$ & $\begin{array}{l}0.269 \pm 0.109 \\
0.107 \pm 0.185 \\
-0.169 \pm 0.188 \\
0.29 \pm 0.146 \\
0.118 \pm 0.277 \\
-0.215 \pm 0.247\end{array}$ & $\begin{array}{l}2.455 \\
0.578 \\
-0.898 \\
1.984 \\
0.428 \\
-0.871\end{array}$ & $\begin{array}{l}.014 \\
.576 \\
.369 \\
.047 \\
.668 \\
.383\end{array}$ \\
\hline head up & $\begin{array}{l}\text { (intercept) } \\
\text { species } \\
\text { condition (control relative to visitors close) } \\
\text { condition (control relative to visitors far) } \\
\text { species*condition (control relative to } \\
\text { visitors close) } \\
\text { species*condition (control relative to } \\
\text { visitors far) }\end{array}$ & $\begin{array}{l}\mathbf{7 . 8 4 1} \pm \mathbf{0 . 3 6 8} \\
-0.95 \pm 0.63 \\
-1.127 \pm 0.425 \\
\mathbf{- 1 . 1 6 2} \pm \mathbf{0 . 3 2 8} \\
0.464 \pm 0.623 \\
0.374 \pm 0.555\end{array}$ & $\begin{array}{l}\mathbf{2 1 . 2 7 4} \\
-1.507 \\
-2.652 \\
\mathbf{- 3 . 5 3 2} \\
0.743 \\
0.674\end{array}$ & $\begin{array}{c}<.001 \\
.162 \\
.008 \\
<.001 \\
.457 \\
.5\end{array}$ \\
\hline vocalizations & $\begin{array}{l}\text { (intercept) } \\
\text { species } \\
\text { condition (control relative to visitors close) } \\
\text { condition (control relative to visitors far) } \\
\text { species*condition (control relative to } \\
\text { visitors close) } \\
\text { species*condition (control relative to } \\
\text { visitors far) }\end{array}$ & $\begin{array}{l}0.043 \pm 0.083 \\
\mathbf{0 . 5 3 1} \pm \mathbf{0 . 1 4 1} \\
-0.036 \pm 0.152 \\
-0.043 \pm 0.118 \\
\mathbf{0 . 7 3 1} \pm \mathbf{0 . 2 2 4} \\
0.218 \pm 0.2\end{array}$ & $\begin{array}{l}0.523 \\
\mathbf{3 . 7 4 7} \\
-0.237 \\
-0.369 \\
\mathbf{3 . 2 5 9} \\
1.092\end{array}$ & $\begin{array}{l}.601 \\
.003 \\
.812 \\
.711 \\
.001 \\
.274\end{array}$ \\
\hline $\begin{array}{l}\text { stress related } \\
\text { behaviors }\end{array}$ & $\begin{array}{l}\text { (intercept) } \\
\text { species } \\
\text { condition (control relative to visitors close) } \\
\text { condition (control relative to visitors far) } \\
\text { species*condition (control relative to } \\
\text { visitors close) } \\
\text { species*condition (control relative to } \\
\text { visitors far) }\end{array}$ & $\begin{array}{l}0.123 \pm 0.068 \\
-0.092 \pm 0.117 \\
0.095 \pm 0.062 \\
0.067 \pm 0.048 \\
-0.093 \pm 0.092 \\
-0.023 \pm 0.082\end{array}$ & $\begin{array}{l}1.799 \\
-0.78 \\
1.523 \\
1.39 \\
-1.009 \\
-0.29\end{array}$ & $\begin{array}{l}.072 \\
.453 \\
.128 \\
.164 \\
.313 \\
\\
.771\end{array}$ \\
\hline
\end{tabular}

Note. Significant values after Bonferroni adjustment $(p \leq .007)$ are highlighted in bold. 
Figure 2

Mean Duration and Standard Error of Head Up in Seconds per Visitors' Condition

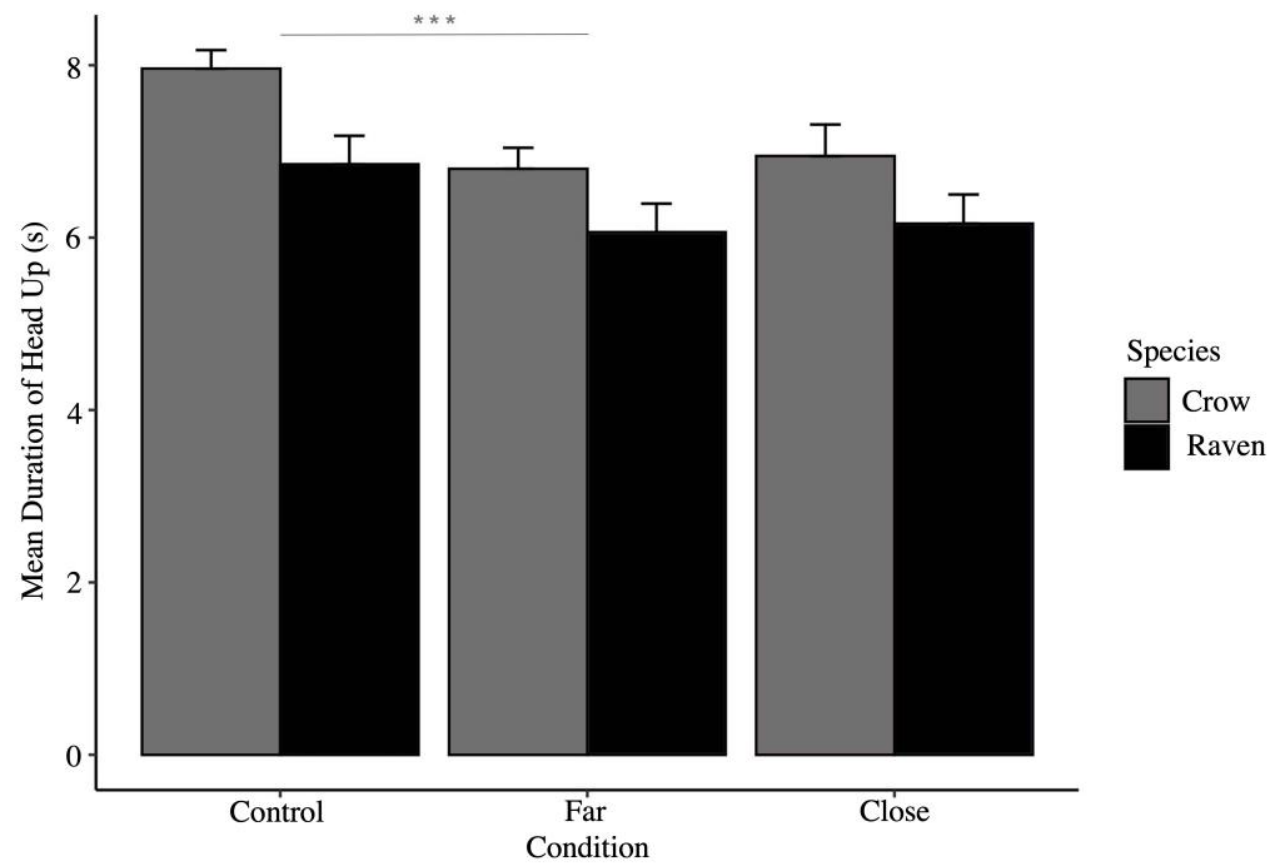

Figure 3

Mean Duration and Standard Error of Vocalizations in Seconds per Visitors' Condition in Crows and Ravens

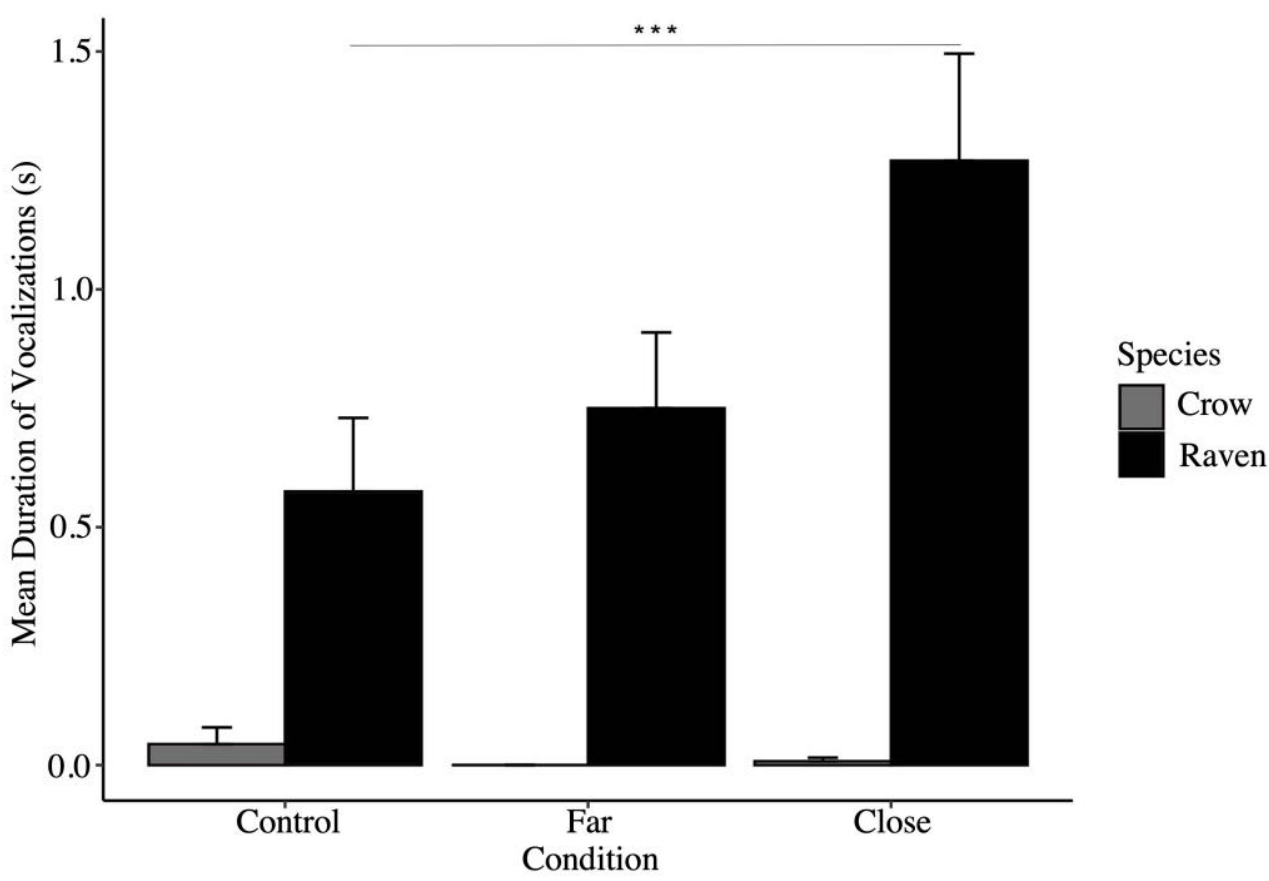




\section{Discussion}

In the present study, we investigated behavioral responses of crows and common ravens to the presence of visitors. In the presence of visitors, crows preened more compared to the control situation, in which no visitors were in sight of the animals. This effect was only shown in crows but not in ravens. Next to its function as feather maintenance, preening in birds is also a displacement behavior, which occurs in stressful situations involving a motivational conflict for the individual (Delius, 1988). Not only did domestic chicks have an increased heart rate as an indicator of the physiological stress response, but also preened more, when subjected to an air-puff as an example of a stressful stimulus (Edgar et al., 2015). However, alternatively, an increase in preening behavior could also be sign of relaxation and comfort (Delius, 1988). Therefore, we cannot conclude whether the increase of duration of preening in crows indicates that the presence of human visitors is perceived as stressful or potentially calming. In contrast to this finding, visitor presence is not related to an increase in preening behavior in common ravens. This could potentially be indicative of a species difference and common ravens being better habituated to human presence; however, it could also be an effect of enclosure design. In our study, aviaries housing common ravens were significantly larger $\left(80 \mathrm{~m}^{2}\right)$ compared to the aviaries in which the crows were housed $\left(20 \mathrm{~m}^{2}\right)$, which also corresponds to a difference in maximum height of the enclosure (crow aviaries: $3.5 \mathrm{~m}$; raven aviaries: $7 \mathrm{~m}$ ). Birds in general prefer to sit on elevated perches (Campbell et al., 2016) and the fitting of aviaries with a good range of perches at different heights is generally recommended to ensure positive welfare (Field \& Thomas, 2000). Alternatively, species differences could potentially also be caused by age and hence potential habituation to human visitors facilitated by longterm housing in captivity. All ravens in the present study hatched in 2009 , whereas the crows hatched between 2007 and 2014, so some of the crows spent significantly less time in captivity. From the present results, we can only speculate that the described species differences are caused by differences in enclosure design or habituation to visitor presence, and further, systematic experiments to investigate this topic would be desirable. In contrast to preening, the duration of stress-related behaviors (shaking, wing quivering and beak wiping) was not affected by the presence of visitors. Duration of feeding and affiliative interactions between conspecifics was also not affected by the presence of visitors. If corvids were disturbed by human presence, we would have predicted a decrease in the duration of feeding and affiliation when visitors were in sight or at least in close proximity to the aviary. Hence, we conclude that the present behavioral data does not indicate human visitors to negatively affect the welfare of captive housed crows and ravens. We have to acknowledge that 'STRANGEness' of our study subjects, i.e., social background of individuals, self-selection, rearing history, acclimation and habituation, natural changes in responsiveness, and genetic make-up (Webster \& Rutz, 2020), could have contributed our findings and we caution from generalizing our findings across different corvid populations and species.

Common ravens vocalized more when visitors were within two meters of their aviary compared to the control condition. This relationship was missing in crows. Corvids belong to the order of Passeriformes (songbirds) with extended vocal repertoires and different, individual call-type uttered in various contexts, e.g., social interactions, food calls, contact calls (Enggist-Dueblin \& Pfister, 2002). In the present study, we did not differentiate between the different call-types uttered in response to visitor presence and therefore can only speculate about the behavioral context. Common ravens have been shown to increase vocalizations in response to social separation (Munteanu et al., 2017), which could be a response to a stressful situation, but also an attempt to establish contact with conspecifics. Vocalizations are used by animals to signal aggression (Szipl et al., 2017) or attract potential cooperation partners (Sierro et al., 2020). As mentioned before, we have not collected data on different contexts of vocalizations, e.g., if they are directed towards the human visitors or the conspecific partner; hence, we cannot tell why ravens increased vocalizations in response to the presence of visitors. Previous studies on visitor effects largely ignored effects on vocal communication and future studies on this topic are highly desirable.

Both corvid species showed less head up behavior when visitors were in sight compared to the control condition. In our study, we defined head up as, a form of vigilance with relaxed body posture, i.e., 
neck not stretched. Head up generally was the most commonly observed behavior and the decrease when visitors were present correlates with an increase in other behaviors; for example, preening in crows or vocalizations in ravens. Overall, we describe only minor behavioral changes of corvids in response to visitor presence, indicating neutral visitor effects. In many contexts, captive animals have been domesticated, e.g., on farms, pets, and thus, adapted to the presence of humans. For example, domestic chickens show little behavioral responses to visitors in an interaction program (Ramont et al., 2021). Typical zoo animals, born in captivity over generations, might have undergone a certain selection for tolerance towards humans (Frankham et al., 1986; McDougall et al., 2006). The observed corvids all hatched in the wild and were hand-raised by humans (crows) or were the first generation hatched in captivity and raised by parents (ravens), hence, no effects of domestication or selection for tameness would have been expected. As such, our study provides evidence of captive, non-domesticated animals habituating to the presence of visitors in a wildlife park environment. Hand-raising and re-enforcing interactions with caretakers and human experimenters may have additionally contributed to corvids not strongly responding to the presence of visitors. Habituation of wild animals to the presence of humans has been previously shown; for example, a captive group of free-ranging ring-tailed lemurs, Lemur catta, showed no behavioral changes to the presence of visitors, indicating habituation to humans (Collins et al., 2017). It has to be taken into consideration that the present study was designed to capture short-term behavioral changes to the presence of visitors. We analyzed periods of ten seconds, with or without humans present. Because of the high variation in time in which visitors were visible to the focal subjects (minimum \pm maximum: $5 \pm 2201 \mathrm{~s}$ ), we decided to standardize the observed time period. This was also done to avoid potential habituation to individual visitors and groups affecting the results. It is very likely that although the observed corvids initially responded to visitors, they might have habituated when visitors spent more time in front of the aviary or in sight. We hence standardized observations and always compared the first ten seconds visitors spent within a respective category (close, far). We conducted our study over a short period in July, when relatively high visitor numbers are to be expected. Further studies on potential long-term effects and seasonal variation would be desirable. For example, we cannot exclude that corvids' behavioral responses to visitors were relatively minor during the period of relatively high visitor numbers, in which we conducted the present study, and that behavioral responses would be stronger in periods of less visitors present. We presently cannot draw any conclusions about potential long-term effects of visitors onto corvid behavior.

Responses to visitors might depend on individual characteristics, e.g., personality. In captive western lowland gorillas, not all individuals of the group show behavioral responses to the presence of visitors (Stoinski et al., 2012). In our study, we found individual identity as a random factor to have a profound effect on the variation described in our data for some behaviors, but not others (0-73\%). Strongest individual variation was described in affiliative (54\%) and stress related behaviors (73\%). This could indicate that, although we did not describe an overall significant effect of visitor presence on the expression of these behaviors, there were substantial individual differences. Least individual variation was described for the behaviors preening $(3 \%)$ and vocalizations $(0 \%)$. Individual differences and potential coping strategies of corvids in response to human presence would thus be an important and interesting topic of investigation in future studies.

The present study contributes novel insights into behavioral responses of non-domesticated avian species to the presence of zoo visitors. Most previous studies on visitors' effects have been conducted on mammals and studies on birds are rare (de Azevedo \& Lima, 2012; Ramont et al., 2021; Sherwen, Magrath, et al., 2015). In order to better understand the effects of zoo visitors on avian welfare, more studies on bird species are necessary. To conclude, although we describe significant behavioral changes in response to visitor presence, the low levels of stress-related behaviors suggest the welfare of the nondomesticated study animals was not profoundly impacted by the presence of visitors. 


\section{Acknowledgments}

Financial support was provided by the University of Vienna, the 'Verein der Förderer der Konrad Lorenz Forschungsstelle' and the 'Herzog von Cumberland Stiftung'. We also would like to thank the editor, Dr Fernandez and three anonymous reviewers for their valuable comments, which helped to improve the manuscript.

Conflict of interest: The authors declare no conflict of interest

\section{References}

Bartoń, K. (2019). MuMIn: Multi-Model Inference. (1.43.6) [Computer software]. https://CRAN.Rproject.org/package=MuMIn

Birke, L. (2002). Effects of browse, human visitors and noise on the behaviour of captive orangutans. Animal Welfare, 11, 189-202.

Blum, C. R., Fitch, W. T., \& Bugnyar, T. (2020). Rapid learning and long-term memory for dangerous humans in ravens (Corvus corax). Frontiers in Psychology, 11, 581794.

Bugnyar, T., Stöwe, M., \& Heinrich, B. (2004). Ravens, Corvus corax, follow gaze direction of humans around obstacles. Proceedings of the Royal Society of London. Series B: Biological Sciences, 271(1546), 13311336.

Campbell, D. L. M., Makagon, M. M., Swanson, J. C., \& Siegford, J. M. (2016). Perch use by laying hens in a commercial aviary. Poultry Science, 95(8), 1736-1742.

Carder, G., \& Semple, S. (2008). Visitor effects on anxiety in two captive groups of western lowland gorillas. Applied Animal Behaviour Science, 115(3-4), 211-220.

Castles, D. L., \& Whiten, A. (2010). Post-conflict behaviour of wild olive baboons. II. Stress and self-directed behaviour. Ethology, 104(2), 148-160.

Choo, Y., Todd, P. A., \& Li, D. (2011). Visitor effects on zoo orangutans in two novel, naturalistic enclosures. Applied Animal Behaviour Science, 133(1-2), 78-86.

Cibulski, L., Wascher, C. A. F., Weiß, B. M., \& Kotrschal, K. (2014). Familiarity with the experimenter influences the performance of Common ravens (Corvus corax) and Carrion crows (Corvus corone corone) in cognitive tasks. Behavioural Processes, 103, 129-137.

Cipolletta, C. (2003). Ranging patterns of a western gorilla group during habituation to humans in the Dzanga-Ndoki national park, Central African Republic. International Journal of Primatology, 24(6), 1207-1226.

Claxton, A. M. (2011). The potential of the human-animal relationship as an environmental enrichment for the welfare of zoo-housed animals. Applied Animal Behaviour Science, 133(1-2), 1-10.

Clucas, B., Marzluff, J. M., Mackovjak, D., \& Palmquist, I. (2013). Do American crows pay attention to human gaze and facial expressions? Ethology, 119(4), 296-302.

Collins, C., Corkery, I., Haigh, A., McKeown, S., Quirke, T., \& O'Riordan, R. (2017). The effects of environmental and visitor variables on the behavior of free-ranging ring-tailed lemurs (Lemur catta) in captivity. Zoo Biology, 36(4), 250-260.

Cooke, C. M., \& Schillaci, M. A. (2007). Behavioral responses to the zoo environment by white handed gibbons. Applied Animal Behaviour Science, 106(1-3), 125-133.

Davey, G. (2006). An hourly variation in zoo visitor interest: Measurement and significance for animal welfare research. Journal of Applied Animal Welfare Science, 9, 249-256.

Davey, G. (2007). Visitors' effects on the welfare of animals in the zoo: A review. Journal of Applied Animal Welfare Science, 10(2), 169-183.

Davidson, G. L., Clayton, N. S., \& Thornton, A. (2015). Wild jackdaws, Corvus monedula, recognize individual humans and may respond to gaze direction with defensive behaviour. Animal Behaviour, 108, 17-24.

de Azevedo, C. S., \& Lima, M. F. F. (2012). Visitor influence on the behavior of captive greater rheas (Rhea americana, Rheidae aves). Journal of Applied Animal Welfare Science, 15(2), 113-125.

de Vere, A. J. (2018). Visitor effects on a zoo population of California sea lions (Zalophus californianus) and harbor seals (Phoca vitulina). Zoo Biology, 37(3), 162-170.

Delius, J. D. (1988). Preening and associated comfort behavior in birds. Annals of the New York Academy of Sciences, 525, 40-55. 
Dufour, V., Wascher, C. A. F., Braun, A., Miller, R., \& Bugnyar, T. (2012). Corvids can decide if a future exchange is worth waiting for. Biology Letters, 8(2), 201-204.

Edgar, J., Held, S., Paul, E., Pettersson, I., I'Anson Price, R., \& Nicol, C. (2015). Social buffering in a bird. Animal Behaviour, 105, 11-19.

Enggist-Dueblin, P., \& Pfister, U. (2002). Cultural transmission of vocalizations in ravens, Corvus corax. Animal Behaviour, 64(6), 831-841.

Farrand, A., Hosey, G., \& Buchanan-Smith, H. M. (2014). The visitor effect in petting zoo-housed animals: Aversive or enriching? Applied Animal Behaviour Science, 151, 117-127.

Fernandez, E. J., Tamborski, M. A., Pickens, S. R., \& Timberlake, W. (2009). Animal-visitor interactions in the modern zoo: Conflicts and interventions. Applied Animal Behaviour Science, 120(1-2), 1-8.

Field, D. A., \& Thomas, R. (2000). Environmental enrichment for psittacines at Edinburgh Zoo. International Zoo Yearbook, 37, 232-237.

Fox, J., \& Weisberg, S. (2011). An \{R\} Companion to Applied Regression. Sage Publications.

Frankham, R., Hemmer, H., Ryder, O. A., Cothran, E. G., Soulé, M. E., Murray, N. D., \& Snyder, M. (1986). Selection in captive populations. Zoo Biology, 5(2), 127-138.

Fraser, O. N., Stahl, D., \& Aureli, F. (2008). Stress reduction through consolation in chimpanzees. Proceedings of the National Academy of Sciences, 105(25), 8557-8562.

Glatston, A. R., Geilvoet-Soeteman, E., Hora-Pecek, E., \& Van Hooff, J. A. R. A. M. (1984). The influence of the zoo environment on social behavior of groups of cotton-topped tamarins, Saguinus oedipus oedipus. Zoo Biology, 3(3), 241-253.

Goodenough, A. E., McDonald, K., Moody, K., \& Wheeler, C. (2019). Are 'visitor effects' overestimated? Behaviour in captive lemurs is mainly driven by co-variation with time and weather. Journal of Zoo and Aquarium Research, 7(2), 59-66.

Greggor, A. L., Clayton, N. S., Fulford, A. J. C., \& Thornton, A. (2016). Street smart: Faster approach towards litter in urban areas by highly neophobic corvids and less fearful birds. Animal Behaviour, 117, 123-133.

Greggor, A. L., Thornton, A., \& Clayton, N. S. (2015). Neophobia is not only avoidance: Improving neophobia tests by combining cognition and ecology. Current Opinion in Behavioral Sciences, 6, 82-89.

Hill, S. P., \& Broom, D. M. (2009). Measuring zoo animal welfare: Theory and practice. Zoo Biology, 28(6), 531544.

Hillemann, F., Bugnyar, T., Kotrschal, K., \& Wascher, C. A. F. (2014). Waiting for better, not for more: Corvids respond to quality in two delay maintenance tasks. Animal Behaviour, 90, 1-10.

Hosey, G. R. (2000). Zoo animals and their human audiences: What is the visitor effect? Animal Welfare, 9(4), 343357.

Huskisson, S. M., Ross, S. R., \& Hopper, L. M. (2020). Do zoo visitors induce attentional bias effects in primates completing cognitive tasks? Animal Cognition 24, 645-653.

Kövér, L., Lengyel, S., Takenaka, M., Kirchmeir, A., Uhl, F., Miller, R., \& Schwab, C. (2019). Why do zoos attract crows? A comparative study from Europe and Asia. Ecology and Evolution, 9(24), 14465-14475.

Larsen, M. J., Sherwen, S. L., \& Rault, J.-L. (2014). Number of nearby visitors and noise level affect vigilance in captive koalas. Applied Animal Behaviour Science, 154, 76-82.

Learmonth, M. J., Sherwen, S., \& Hemsworth, P. H. (2018). The effects of zoo visitors on Quokka (Setonix brachyurus) avoidance behavior in a walk-through exhibit. Zoo Biology, 37(4), 223-228.

Maia, C. M., Volpato, G. L., \& Santos, E. F. (2012). A case study: The effect of visitors on two captive pumas with respect to the time of the day. Journal of Applied Animal Welfare Science, 15(3), 222-235.

Mallapur, A., Sinha, A., \& Waran, N. (2005). Influence of visitor presence on the behaviour of captive lion-tailed macaques (Macaca silenus) housed in Indian zoos. Applied Animal Behaviour Science, 94(3-4), 341-352.

Maple, T. L., \& Perdue, B. M. (2013). Zoo animal welfare. Berlin: Springer.

Marzluff, J. M., Miyaoka, R., Minoshima, S., \& Cross, D. J. (2012). Brain imaging reveals neuronal circuitry underlying the crow's perception of human faces. Proceedings of the National Academy of Sciences, 109(39), 15912-15917.

Marzluff, J. M., Walls, J., Cornell, H. N., Withey, J. C., \& Craig, D. P. (2010). Lasting recognition of threatening people by wild American crows. Animal Behaviour, 79(3), 699-707.

McDougall, P. T., Réale, D., Sol, D., \& Reader, S. M. (2006). Wildlife conservation and animal temperament: Causes and consequences of evolutionary change for captive, reintroduced, and wild populations. Animal Conservation, 9(1), 39-48.

Müller, J. J. A., Massen, J. J. M., Bugnyar, T., \& Osvath, M. (2017). Ravens remember the nature of a single reciprocal interaction sequence over 2 days and even after a month. Animal Behaviour, 128, 69-78. 
Munteanu, A. M., Stocker, M., Stöwe, M., Massen, J. J. M., \& Bugnyar, T. (2017). Behavioural and hormonal stress responses to social separation in ravens, Corvus corax. Ethology, 123(2), 123-135.

Nakagawa, S., \& Schielzeth, H. (2013). A general and simple method for obtaining R2 from generalized linear mixed-effects models. Methods in Ecology and Evolution, 4(2), 133-142.

Pinheiro, J., Bates, D., DebRoy, S., \& Sarkar, D. (2020). nlme: Linear and Nonlinear Mixed Effects Models. (R package version 3.1-151) [Computer software]. https://CRAN.R-project.org/package=nlme

Queiroz, M., \& Young, R. (2018). The different physical and behavioural characteristics of zoo mammals that influence their response to visitors. Animals, 8(8), 139.

R Core Team (2021). R: A language and environment for statistical computing. R Foundation for Statistical Computing, Vienna, Austria. https://www.R-project.org/.

Rajagopal, T., Archunan, G., \& Sekar, M. (2011). Impact of zoo visitors on the fecal cortisol levels and behavior of an endangered species: Indian Blackbuck (Antelope cervicapra L.). Journal of Applied Animal Welfare Science, 14(1), 18-32.

Ramont, M., Leahy, M., \& Cronin, K. A. (2021). Domestic animal welfare at the zoo: The impact of an animal visitor interaction program on chickens. Animal Behavior and Cognition, 8(1), 1-14.

Sekar, M., Rajagopal, T., \& Archunan, G. (2008). Influence of zoo visitor presence on the behavior of captive Indian gaur (Bos gaurus gaurus) in a zoological park. Journal of Applied Animal Welfare Science, 11(4), 352-357.

Sellinger, R. L., \& Ha, J. C. (2005). The effects of visitor density and intensity on the behavior of two captive jaguars (Panthera onca). Journal of Applied Animal Welfare Science, 8(4), 233-244.

Sherwen, S. L., Harvey, T. J., Magrath, M. J. L., Butler, K. L., Fanson, K. V., \& Hemsworth, P. H. (2015). Effects of visual contact with zoo visitors on black-capped capuchin welfare. Applied Animal Behaviour Science, $167,65-73$.

Sherwen, S. L., \& Hemsworth, P. H. (2019). The visitor effect on zoo animals: Implications and opportunities for zoo animal welfare. Animals, 9(6), 366.

Sherwen, S. L., Hemsworth, P. H., Butler, K. L., Fanson, K. V., \& Magrath, M. J. L. (2015). Impacts of visitor number on kangaroos housed in free-range exhibits: Kangaroo welfare in free-range exhibits. Zoo Biology, 34(4), 287-295.

Sherwen, S. L., Magrath, M. J. L., Butler, K. L., \& Hemsworth, P. H. (2015). Little penguins, Eudyptula minor, show increased avoidance, aggression and vigilance in response to zoo visitors. Applied Animal Behaviour Science, 168, 71-76.

Sherwen, S. L., Magrath, M. J. L., Butler, K. L., Phillips, C. J. C., \& Hemsworth, P. H. (2014). A multi-enclosure study investigating the behavioural response of meerkats to zoo visitors. Applied Animal Behaviour Science, 156, 70-77.

Sierro, J., Loretto, M., Szipl, G., Massen, J. J. M., \& Bugnyar, T. (2020). Food calling in wild ravens (Corvus corax) revisited: Who is addressed? Ethology, 126(2), 257-266.

Spreafico, M., Szipl, G., Kotrschal, K., \& Wascher, C. A. F. (2012). Physiological and behavioural response in carrion crows (Corvus corone corone) after relocation to a new environment. Wiener Tierärztliche Monatsschrift, 99(Suppl 1), 61.

Stevens, J. M. G., Thyssen, A., Laevens, H., \& Vervaecke, H. (2013). The influence of zoo visitor numbers on the behaviour of harbour seals. Journal of Zoo and Aquarium Research, 1(1), 31-34.

Stoinski, T. S., Jaicks, H. F., \& Drayton, L. A. (2012). Visitor effects on the behavior of captive western lowland gorillas: The importance of individual differences in examining welfare. Zoo Biology, 31(5), 586-599.

Szipl, G., Ringler, E., Spreafico, M., \& Bugnyar, T. (2017). Calls during agonistic interactions vary with arousal and raise audience attention in ravens. Frontiers in Zoology, 14(1), 57.

Todd, P. A., Macdonald, C., \& Coleman, D. (2007). Visitor-associated variation in captive Diana monkey (Cercopithecus diana diana) behaviour. Applied Animal Behaviour Science, 107(1-2), 162-165.

Troisi, A. (2002). Displacement activities as a behavioral measure of stress in nonhuman primates and human subjects. Stress, 5(1), 47-54.

Wascher, C. A. F., Szipl, G., Boeckle, M., \& Wilkinson, A. (2012). You sound familiar: Carrion crows can differentiate between the calls of known and unknown heterospecifics. Animal Cognition, 15(5), 10151019.

Webster, M. M., \& Rutz, C. (2020). How STRANGE are your study animals? Nature, 582(7812), 337-340.

Wells, D. L. (2005). A note on the influence of visitors on the behaviour and welfare of zoo-housed gorillas. Applied Animal Behaviour Science, 93(1-2), 13-17.

Zuur, A. F., Ieno, E. N., Walker, N. J., Saveliev, A. A., \& Smith, G. M. (2009). Mixed Effects Models and Extension in Ecology With R. Springer. 